\title{
The relationship between multiple chronic diseases and depressive symptoms among middle-aged and elderly populations: results of a 2009 korean community health survey of 156,747 participants
} JooYeon Seo ${ }^{1,2}$, BoYoul Choi ${ }^{1,2}$, Shinah Kim ${ }^{3}$, HyeYoung Lee ${ }^{1,2}$ and DongHoon Oh ${ }^{1,4^{*}}$ (D)

\begin{abstract}
Background: The purpose of this study was to investigate the relationship between multiple chronic diseases and depressive symptoms in middle-aged and elderly populations.

Methods: This study was performed using the 2009 Korean Community Health Survey, which targeted adults over the age of 40 ( $N=156,747$ participants, 88,749 aged $40-59$ years and 67,998 aged $\geq 60$ years). The Korean version of the Center for Epidemiologic Studies Depression Scale (CES-D-K) was used as the measurement tool for depressive symptoms (CES-D-K score over 16). Multiple chronic diseases were defined as the concurrent presence of two or more chronic diseases.

Results: The prevalence and risk ratios (RRs) of experiencing depressive symptoms increased in the presence of multiple chronic diseases and with the number of comorbidities. The RRs of experiencing depressive symptoms according to the presence of multiple chronic diseases were higher in the middle-aged population (adjusted RR, $1.939,95 \%$ confidence limits (CL), 1.82-2.06) than in the elderly population (adjusted RR, 1.620, 95\% CL, 1.55-1.69). In particular, middle-aged women who suffer from 4 or more chronic diseases have the highest RR (adjusted RR, 4.985, 95\% CL, 4.13-6.03) for depressive symptoms.

Conclusions: Multiple chronic diseases are closely associated with depressive symptoms in middle-aged and elderly populations. Given the mutual relationship between multiple chronic diseases and depressive symptoms, attention to and the assessment of depressive symptoms are needed in people with multiple chronic diseases.
\end{abstract}

Keywords: Community surveys, Comorbidity, Depressive symptoms, Epidemiologic studies, Republic of Korea

\section{Background}

To date, many researchers and clinicians have studied the relationship between the presence of chronic diseases and depression [1-4]. Most middle-aged or elderly patients with major chronic diseases have a higher chance of developing depression. For example, $18-28 \%$ of adults with diabetes, $16.7 \%$ of adults with hypertension experience

\footnotetext{
* Correspondence: seulhahmc@gmail.com

${ }^{1}$ Institute for Health and Society, College of Medicine, Hanyang University,

222 Wangsimni-ro, Sungdong-Gu, Seoul 04763, South Korea

${ }^{4}$ Seulha Mental Health Clinic, Jeju, South Korea

Full list of author information is available at the end of the article
}

depression. These numbers are higher than those in groups without chronic diseases [5, 6]. A previous study suggested that patients with diabetes, vascular diseases, and cancer who experience depression tend to die 5 to 10 years earlier than patients without any psychiatric diseases [7]. However, previous studies mainly studied the relationship between depressive symptoms and chronic diseases in adults over 55 years old [8-11]. Consequently, we need to figure out the mutual influence by analyzing the relationship between chronic illnesses and depressive symptoms, among others, by means of indicating deterioration, increasing disability and economic burden $[2,9,12]$. 
Multiple chronic diseases (MCDs) also known as comorbidity are defined as two or more chronic diseases. The prevalence of MCDs and the management of these conditions has become an important public health issue [13-16]. Up to date, several studies have investigated the impact of MCDs on depression, as well as the relationship between specific chronic diseases and depression $[3,15,17,18]$. However, few studies have targeted middle-aged or younger populations compared with elderly populations $[1,10,19,20]$. A previous study reported the relationship between chronic physical conditions and depression in patients aged 22-64 years and considered the differences in the age groups [19]. The study focused on each chronic disease individually and on only younger adults [19]. In addition, previous studies investigated the relationship between MCDs and depression itself, but the effect of the numbers of chronic diseases on depression has not been studied $[1,6,21]$. Hence, the effect of MCDs and the number of chronic diseases on depression in a younger population, such as a middle-aged population, has not been explicitly studied.

Therefore, we estimated the prevalence depressive of depressive symptoms and MCD, and studied the relationship between MCDs and depressive symptoms in middle-aged and elderly populations using data from a large, representative national sample obtained through a community health survey in Republic of Korea (below, Korea). The specific objectives of this study were to estimate the prevalence of depressive symptoms and MCDs and to investigate the relationship between MCDs and depressive symptoms in these age groups.

\section{Methods}

\section{Data and participants}

This study was performed using the data from the Korean Community Health Survey (KCHS) conducted by the Korean Centers for Disease Control and Prevention (KCDC) in 2009. The KCHS has been a national health survey with direct face-to-face interviewing by a trained interviewer, and 253 national public health centers have participated annually since 2008. The KCHS has public confidence and represents the entire population of Korea. It is secondary data produced by the Korean government for the purpose of public use and is designed as a cross sectional study [https://chs.cdc.go.kr/chs/intro.html]. The aims of the KCHS are to calculate the health statistics of city and county units to establish regional health plans, to produce basic data to systematically assess the local health service, to expand the community surveillance infrastructure by establishing public cooperation, and to perform a standardized survey to compare the health of the population [22]. The KCHS 2009 was conducted from September to November 2009 on study participants aged 19 or older in each area who were selected by the probability proportional sampling method and the systematic sampling method. The KCHS collects detailed information, including sociodemographic characteristics, 15 types of chronic diseases in the individual's past medical history data (defined as "diseases diagnosed by medical doctors"), lifestyle, behaviors, and healthrelated problems. The KCHS protocol is annually reviewed and approved by the institutional review board of the KCDC. Written informed consent was obtained from all participants in the KCHS. No additional institutional review board approval was required for this study because the data were intended for public purposes [23]. The 2009 KCHS included 230,715 participants [24]. We excluded 73,659 participants under the age of 40 years due to the low prevalence of chronic diseases in this population. In fact, as shown in previous studies, the prevalence of MCDs and chronic diseases, such as hypertension and diabetes, in individuals less than 40 years of age is relatively low $[25,26]$. The prevalence of MCDs is only $0.4 \%$ in individuals in their $20 \mathrm{~s}$ and $1.4 \%$ in those in their $30 \mathrm{~s}$. In contrast, the prevalence of MCDs is $11.9 \%$ in those aged $40-59$ years and $46.3 \%$ in those aged $\geq 60$ years in the 2009 KCHS. In addition, this study focused on comparing middle-aged and elderly populations. For these reasons, participants under the age of 40 years were excluded from the study. Moreover, 309 individuals who did not provide complete information on the questionnaire were excluded from this study (206 individuals had missing data on MCDs, and 103 individuals had a missing Center for Epidemiologic Studies Depression Scale (CES-D-K) score). Finally, a total of 156,747 participants $(88,749$ aged 40-59 years and 67,998 aged $\geq 60$ years; 71,695 men and 85,052 women) were included in the study. The participant selection process is shown in Fig. 1.

\section{Sociodemographic variables}

The participants were divided into age groups, namely, 40-59 years and 60 years or over, for comparisons between the middle-aged and elderly populations. Marital status was classified as follows: married, separated, divorced, widowed, and never married. Employment was classified as yes/no. Occupational categories were classified into manual, non-manual, and unemployed/others. The category of other occupations included students and housewives. Educational status was classified as not educated, elementary school, middle school, high school, and college or more. The average monthly household family income of the participants was classified as 1 million won (Korean currency unit) or less, 2 million won or less, 3 million won or less, 4 million won or less, and 4.01 million won or more. It is the monthly average of the past one year of actual income of all household 




Fig. 1 Study participants

members except taxes. One thousand won roughly equals one US dollar. The residence locations were classified into four groups according to the Korean administrative districts, which are based on population size: (1) county (population less than 50,000), (2) small city (population more than 50,000), (3) medium city (population more than 500,000), and (4) metropolitan area (population more than 1,000,000). All questionnaires were conducted through one-on-one interviews.

\section{Independent variables: Chronic diseases}

The 2009 KCHS covered 15 chronic medical diseases: (1) diabetes, (2) dyslipidemia, (3) hypertension, (4) angina, (5) myocardial infarction, (6) stroke, (7) osteoporosis, (8) arthritis, (9) tuberculosis, (10) asthma, (11) hepatitis B, (12) atopic dermatitis, (13) allergic rhinitis, (14) cataract, and (15) depression. All chronic diseases were investigated with the following question: "Have you ever been diagnosed with any specific disease by a physician in your lifetime?" We used the number of comorbid chronic diseases to define the MCDs. MCDs were defined as the concurrent presence of two or more chronic diseases. Tuberculosis can be cured, but the treatment period can last for more than six months; therefore, tuberculosis affects the individual's quality of life and is not only an endemic disease but also one of the highest public health priorities in Korea. Therefore, we included tuberculosis as an important medical disease despite it being treatable [27].

\section{Dependent variables: Depressive symptoms}

We used depressive symptoms as a dependent variable. Commonly, depressive symptoms include low mood, feeling fatigue, anxiety, reducing self-esteem, and sleep disturbance [28]. Also, the survey about depressive symptoms is an effective tool for screening depression [29].

The 2009 KCHS used the Korean-validated 20-item version of the CES-D-K to assess depressive symptoms [30] and the definition of depressive symptoms is equal to or greater than a CES-D-K score of 16 [31]. The CES$\mathrm{D}$ was not originally developed to generate a clinical diagnosis of depression, but to detect individuals with depressive symptoms. The CES-D has been translated into Korean, and its reliability and validity have been confirmed [32]. Cho et al. suggested two optimal cut-off points: one is the universal cut-off point of 16 , which effectively detects and assesses 'probable' depressive symptoms; the other is 25 , which more accurately corresponds to the DSM-III-R classification of major depression and is regarded as the cut-off point for indicating severe, 'definite' depression symptoms [33]. 
This scale is designed to identify the existence of depressive symptoms and evaluate their severity. It is a 20 -item measure consisting of 4 positively worded items and 16 negatively worded items. The positive items are reversecoded so that the scores have a potential range of 0 to 60 , with higher scores indicating the presence of more depressive symptoms [23]. The internal consistency of the Korean version of the CES-D-K was verified in 1993 by Cho et al. (Cronbach's alpha $=0.9098)$ [32].

\section{Statistical analysis}

All analyses were stratified by age group for comparisons between the middle-aged and elderly populations. Chisquare tests were used to examine the significance of the differences in the sociodemographic characteristics, numbers of chronic diseases, presence of depressive symptoms and MCDs, and depression diagnosed by physicians between the age groups. The CES-D-K scores are expressed as the medians and interquartile ranges (IQRs) and compared by age group using Mann-Whitney U test. The scores were transformed to a natural logarithm because they did not follow a normal distribution.

The prevalence of depressive symptoms and the CES$\mathrm{D}-\mathrm{K}$ scores were described for each disease. The severity of the depressive symptoms according to the disease state or number of diseases was described as the median and IQR of the CES-D-K scores, and the $p$-values were calculated using Student's t-test to compare two groups (presence of each disease or MCDs) or ANOVA (Analysis of Variance) to compare three or more groups (the groups distinguished by the number of diseases)..

We performed a multivariate logistic regression analysis to assess the relationship between depressive symptoms and each chronic disease, MCDs, and number of diseases. Multivariate logistic regression analyses were performed to calculate the adjusted risk ratios (RRs) and 95\% confidence limits (CLs) by adjusting for variables affecting the depressive symptoms, such as age (years), gender (except when the results were stratified by gender), marital status, employment, occupational categorization, education, monthly income, and residence location [34], and each disease to correct for the influence of other diseases and analyze the depressive symptoms in each disease. $P$ values $<0.05$ were considered statistically significant, and all statistical analyses were performed with SAS 9.4 (SAS Inc., Cary, NC, USA).

\section{Results}

Table 1 shows the sociodemographic characteristics of the study population according to age group. There were statistically significant differences between the two groups in all variables $(p<0.001)$. A total of $11.88 \%$ of middle-aged individuals had MCDs, and $46.27 \%$ of the elderly population had MCDs. This value was significantly higher in elderly than that for the middle-aged population $(p<0.001)$. Approximately $1 \%$ of the middleaged population and $9.5 \%$ of the elderly population had 4 or more chronic diseases $(p<0.001)$. The prevalence of depressive symptoms in the elderly population $(17.32 \%)$ was significantly higher than that in the middle-aged population $(9.59 \%)(p<0.001)$. However, the prevalence of depression diagnosed by physicians was $2.77 \%$ and $3.58 \%$, respectively.

Table 2 presents the prevalence, RRs of having depressive symptoms, and CES-D-K scores (median, IQR) for each chronic disease category. The adjusted RRs were statistically significant except for hypertension in the middle-aged population dyslipidemia, and hypertension in the elderly population. Especially, the RRs of the individuals with hypertension experiencing depressive symptoms were not significant in either group. The adjusted RRs for experiencing depressive symptoms with stroke were higher than those for any other disease in the 40to 59-year-old population (adjusted RR, 2.336, 95\% CL, 1.98-2.75) and over 60 years old (adjusted RR, 2.408, 95\% CL, 2.23-2.60). Accordingly, the CES-D-K scores were the highest in the individuals with stroke (median: 8, IQR: $3-18$ in the middle-aged population and median: 10, IQR: 4-20 in the elderly population). In addition, the RRs of the individuals with dyslipidemia experiencing depressive symptoms were not significant in the elderly population. Overall, the RRs of the patients with all diseases experiencing depressive symptoms were higher in the middle-aged population than in the elderly population, except for stroke and allergic rhinitis, in which the CES-D-K scores in patients with these diseases were significantly higher than in those without these diseases.

Table 3 shows that the prevalence, RRs for experiencing depressive symptoms, and CES-D-K scores increased in the presence of MCDs and with the number of chronic diseases $(0,1,2,3$ and more than 4 diseases). The RRs of experiencing depressive symptoms in individuals with MCDs (yes/no) were higher in the middle-aged population (adjusted RR, 1.939, 95\% CL, 1.82-2.06) than in the elderly population (adjusted RR, 1.620, 95\% CL, 1.55-1.49). In particular, the RRs of experiencing depressive symptoms increased dramatically in the middle-aged patients with more than four diseases (adjusted RR, 4.465, 95\% CL, 3.815.23). The extent of the increase in the CES-D-K score was higher in the middle-aged population than in the elderly population. In addition, we performed additional analyses stratified by gender (men and women) (Additional file 1: Table S1 and Additional file 2: Figure S1).

We investigated the differences between the three groups; 0 vs. 1 vs. 2 or more diseases (MCDs) for examining the effects of 1 single disease vs. 0. In all four groups, the RRs of having depressive symptoms and the CES-D-K scores in the single disease participants were significantly greater than in those with no chronic 
Table 1 Sociodemographic and clinical characteristics of the study population

\begin{tabular}{|c|c|c|c|c|c|}
\hline & \multirow{2}{*}{\multicolumn{2}{|c|}{$\begin{array}{l}40-59 \text { yr } \\
\text { (No. participants }=88,749 \text { ) }\end{array}$}} & \multirow{2}{*}{\multicolumn{2}{|c|}{$\begin{array}{l}\geq 60 \mathrm{yr} \\
\text { (No. participants }=67,998)\end{array}$}} & \multirow[t]{3}{*}{$p^{a}$} \\
\hline & & & & & \\
\hline & $n$ & $\%$ & $n$ & $\%$ & \\
\hline \multicolumn{6}{|l|}{ Gender } \\
\hline Men & 42,961 & 48.41 & 28,734 & 42.26 & \multirow[t]{2}{*}{$<0.001$} \\
\hline Women & 45,788 & 51.59 & 39,264 & 57.74 & \\
\hline \multicolumn{6}{|l|}{ Marital status } \\
\hline With spouse & 72,945 & 82.19 & 43,552 & 64.05 & \multirow[t]{5}{*}{$<0.001$} \\
\hline Separated & 4459 & 5.02 & 1746 & 2.57 & \\
\hline Divorced & 4698 & 5.29 & 1081 & 1.59 & \\
\hline Widowed & 3474 & 3.91 & 21,286 & 31.3 & \\
\hline Never married & 3173 & 3.58 & 333 & 0.49 & \\
\hline \multicolumn{6}{|l|}{ Employment } \\
\hline No & 4527 & 5.1 & 22,956 & 33.76 & \multirow[t]{3}{*}{$<0.001$} \\
\hline Yes & 84,170 & 94.84 & 45,029 & 66.22 & \\
\hline Unknown & 52 & 0.06 & 13 & 0.02 & \\
\hline \multicolumn{6}{|l|}{ Occupational categories } \\
\hline Manual & 31,572 & 35.57 & 21,798 & 32.06 & \multirow[t]{4}{*}{$<0.001$} \\
\hline Non-manual & 33,635 & 37.9 & 5012 & 7.37 & \\
\hline Unemployed/other ${ }^{b}$ & 23,490 & 26.47 & 41,175 & 60.55 & \\
\hline Unknown & 52 & 0.06 & 13 & 0.02 & \\
\hline \multicolumn{6}{|l|}{ Education } \\
\hline College or more & 19,617 & 22.1 & 3384 & 4.98 & \multirow[t]{5}{*}{$<0.001$} \\
\hline High school & 36,308 & 40.91 & 8389 & 12.34 & \\
\hline Middle school & 16,603 & 18.71 & 8492 & 12.49 & \\
\hline Elementary School & 13,192 & 14.86 & 23,112 & 33.99 & \\
\hline Non-educated & 3029 & 3.41 & 24,621 & 36.21 & \\
\hline \multicolumn{6}{|c|}{ Income (Korean 10,000won/month) } \\
\hline 4.01 million won or more & 17,966 & 20.24 & 4418 & 6.5 & \multirow[t]{6}{*}{$<0.001$} \\
\hline 4 million won or less & 11,184 & 12.6 & 3097 & 4.55 & \\
\hline 3 million won or less & 20,672 & 23.29 & 7242 & 10.65 & \\
\hline 2 million won or less & 21,260 & 23.96 & 13,571 & 19.96 & \\
\hline 1 million won or less & 14,562 & 16.41 & 37,459 & 55.09 & \\
\hline Unknown & 3105 & 3.5 & 2211 & 3.25 & \\
\hline \multicolumn{6}{|l|}{ Residence location $^{d}$} \\
\hline County & 27,708 & 31.22 & 32,409 & 47.66 & \multirow[t]{4}{*}{$<0.001$} \\
\hline Small city & 26,235 & 29.56 & 17,741 & 26.09 & \\
\hline Middle city & 9543 & 10.75 & 4137 & 6.08 & \\
\hline Metropolitan & 25,263 & 28.47 & 13,711 & 20.16 & \\
\hline \multicolumn{6}{|l|}{ No. of chronic diseases } \\
\hline 0 & 57,127 & 64.37 & 16,685 & 24.54 & \multirow[t]{4}{*}{$<0.001$} \\
\hline 1 & 21,076 & 23.75 & 19,853 & 29.2 & \\
\hline 2 & 7351 & 8.28 & 15,520 & 22.82 & \\
\hline 3 & 2332 & 2.63 & 9505 & 13.98 & \\
\hline
\end{tabular}


Table 1 Sociodemographic and clinical characteristics of the study population (Continued)

\begin{tabular}{|c|c|c|c|c|c|}
\hline & \multirow{2}{*}{\multicolumn{2}{|c|}{$\begin{array}{l}40-59 \text { yr } \\
\text { (No. participants }=88,749 \text { ) }\end{array}$}} & \multirow{2}{*}{\multicolumn{2}{|c|}{$\begin{array}{l}\geq 60 \mathrm{yr} \\
\text { (No. participants }=67,998)\end{array}$}} & \multirow[t]{3}{*}{$p^{a}$} \\
\hline & & & & & \\
\hline & $n$ & $\%$ & $n$ & $\%$ & \\
\hline 4 or more & 863 & 0.97 & 6435 & 9.46 & \\
\hline \multicolumn{6}{|l|}{ Multiple chronic diseases } \\
\hline No (chronic diseases $0-1$ ) & 78,203 & 88.12 & 36,538 & 53.73 & \multirow[t]{2}{*}{$<0.001$} \\
\hline Yes (chronic diseases $\geq 2$ ) & 10,546 & 11.88 & 31,460 & 46.27 & \\
\hline \multicolumn{6}{|l|}{ Depressive symptoms } \\
\hline No (CES-D-Ke 0-15) & 80,234 & 90.41 & 56,219 & 82.68 & \multirow[t]{2}{*}{$<0.001$} \\
\hline Yes (CES-D-Ke $\geq 16)$ & 8515 & 9.59 & 11,779 & 17.32 & \\
\hline CES-D-K (median, IQR) & 3 & $1-3$ & 5 & $2-12$ & $<0.001$ \\
\hline \multicolumn{6}{|c|}{ Depression diagnosed by physicians } \\
\hline No & 86,291 & 97.23 & 65,567 & 96.42 & \multirow[t]{2}{*}{$<0.001$} \\
\hline Yes & 2458 & 2.77 & 2431 & 3.58 & \\
\hline
\end{tabular}

${ }^{\mathrm{a}} \mathrm{P}$-values were obtained using the chi-square or Mann Whitney $\mathrm{U}$ test with the CES-D-K scores

bIncluding housewives

'One thousand won roughly equals one US dollar

${ }^{\mathrm{d}}$ County; population less than 50,000

Small city; population more than 50,000

Middle city; population more than 500,000

Metropolitan; population more than 1,000,000

${ }^{\mathrm{e}} \mathrm{CES}-\mathrm{D}-\mathrm{K}$; Korean version of the Center for Epidemiological Studies Depression

diseases. The RRs in the middle-aged groups were elevated compared with those in the elderly group (Additional file 1: Table S1). We illustrated that the RRs of the participants with depressive symptoms increased as the number of comorbidities increased (Additional file 2: Figure S1). As shown, as the number of comorbidities increases, the RRs increased to a greater extent in the middle-aged group than in the elderly group. The patterns between the men and women in the same age groups were similar, but the RRs of having depressive symptoms in those with 4 or more diseases was the highest in the middle-aged women (adjusted RR, 4.985, 95\% CL, 4.13-6.03).

\section{Discussion}

Our study investigated the relationship between MCDs and depressive symptoms in the largest sample of middleaged and elderly South Koreans examined to date.

We found that MCDs were associated with increases in the prevalence, severity, and RRs for experiencing depressive symptoms in both middle-aged and elderly people. However, as the numbers of comorbidities increased, the RRs of experiencing depressive symptoms increased to a greater extent in the middle-aged population than in the elderly population. When analyzing the results stratified by gender, the patterns in the same age groups were similar between the men and women. As the number of diseases increased, as depressive symptoms increased in both men and women.
Previous studies have reported an association between higher levels of depression and the presence of MCDs $[10,11,15,17,19]$. For example, the results from a US study conducted through telephone interviews indicated that multiple chronic conditions, particularly pulmonary diseases, increased the risk of depression [15]. In our study, there was a high association between depressive symptoms and certain chronic diseases, particularly angina, myocardial infarction, and stroke. In particular, our study showed that the greatest RRs of experiencing depressive symptoms were observed in both middle-aged and elderly individuals with stroke.

Our results are in line with those of previous studies $[8,21,35]$. Diseases such as stroke and myocardial infarction are associated with severe and persistent symptoms, disabilities, and high mortality rates, regardless of gender and age. Numerous studies have analyzed disability and depression following stroke and myocardial infarction [36-39]. Stroke leads to post-stroke depression (PSD) following the associated physical and cognitive impairments [38, 39]. PSD is caused by various biological mechanisms, such as anatomical damage, particularly a left frontal lesion of the brain and neuronal cell damage induced by pro-inflammatory cytokines, such as interleukin (IL)-1, IL-6, and IL-8 [38]. However, the RRs of experiencing depressive symptoms did not increase in the individuals with hypertension or dyslipidemia, the latter of which is generally asymptomatic or can be prevented and controlled by medication. Taken together, our results suggest that we should consider the 
Table 2 Prevalence and Risk ratios of depressive symptoms according to individual chronic disease

\begin{tabular}{|c|c|c|c|c|c|c|c|c|c|c|c|c|c|}
\hline & & \multicolumn{6}{|c|}{$\begin{array}{l}40-59 \mathrm{yr} \\
\text { (No. participants }=88,749 \text { ) }\end{array}$} & \multicolumn{6}{|c|}{$\begin{array}{l}\geq 60 \mathrm{yr} \\
\text { (No. participants }=67,998)\end{array}$} \\
\hline & & \multirow{2}{*}{$\begin{array}{l}\text { Prevalence } \\
\text { (\%) }\end{array}$} & \multirow{2}{*}{$\begin{array}{l}\text { Adjusted } \\
\text { risk ratio }^{a}\end{array}$} & \multirow[t]{2}{*}{$95 \% \mathrm{CL}^{b}$} & \multicolumn{3}{|l|}{ CES-D-K ${ }^{c}$} & \multirow{2}{*}{$\begin{array}{l}\text { Prevalence } \\
\text { (\%) }\end{array}$} & \multirow{2}{*}{$\begin{array}{l}\text { Adjusted } \\
\text { risk ratio }\end{array}$} & \multirow[t]{2}{*}{$95 \% \mathrm{CL}^{b}$} & \multicolumn{3}{|c|}{ CES-D-K } \\
\hline & & & & & Median & IQR & $p^{d}$ & & & & Median & $\mathrm{IQR}$ & $p^{d}$ \\
\hline \multirow[t]{2}{*}{ Diabetes } & Yes & 15.33 & 1.362 & $1.25-1.49$ & 4 & $1-10$ & $<0.001$ & 21.18 & 1.21 & $1.14-1.28$ & 6 & $2-14$ & $<0.001$ \\
\hline & No & 9.21 & & & 3 & $0-8$ & & 16.63 & & & 5 & $2-11$ & \\
\hline \multirow[t]{2}{*}{ Dyslipidemia } & Yes & 13.4 & 1.274 & $1.18-1.38$ & 4 & $1-9$ & $<0.001$ & 18.91 & 1.026 & $0.96-1.11$ & 6 & $2-13$ & $<0.001$ \\
\hline & No & 9.26 & & & 3 & $0-8$ & & 17.16 & & & 5 & $2-12$ & \\
\hline \multirow[t]{2}{*}{ Hypertension } & Yes & 12.1 & 1.066 & $0.99-1.14$ & 3 & $1-9$ & $<0.001$ & 19.26 & 0.956 & $0.92-1.00$ & 6 & $2-13$ & $<0.001$ \\
\hline & No & 9.12 & & & 3 & $0-8$ & & 15.83 & & & 5 & $1-11$ & \\
\hline \multirow[t]{2}{*}{ Angina } & Yes & 22.41 & 1.725 & $1.43-2.08$ & 5 & $1-14$ & $<0.001$ & 26.13 & 1.386 & $1.25-1.53$ & 7 & $3-16$ & $<0.001$ \\
\hline & No & 9.47 & & & 3 & $1-8$ & & 16.99 & & & 5 & $2-12$ & \\
\hline \multirow{2}{*}{$\begin{array}{l}\text { Myocardial } \\
\text { infarction }\end{array}$} & Yes & 23.21 & 1.695 & $1.35-2.12$ & 6 & $2-14$ & $<0.001$ & 27.53 & 1.555 & $1.39-1.74$ & 7 & $2-17$ & $<0.001$ \\
\hline & No & 9.5 & & & 3 & $1-8$ & & 17.02 & & & 5 & $2-12$ & \\
\hline \multirow[t]{2}{*}{ Stroke } & Yes & 31.21 & 2.336 & $1.98-2.75$ & 8 & $3-18$ & $<0.001$ & 34.59 & 2.408 & $2.23-2.60$ & 10 & $4-20$ & $<0.001$ \\
\hline & No & 9.38 & & & 3 & $1-8$ & & 16.28 & & & 5 & $2-11$ & \\
\hline \multirow[t]{2}{*}{ Osteoporosis } & Yes & 20.91 & 1.599 & $1.44-1.78$ & 6 & $2-14$ & $<0.001$ & 26.47 & 1.328 & $1.26-1.40$ & 8 & $3-16$ & $<0.001$ \\
\hline & No & 9.22 & & & 3 & $0-8$ & & 15.31 & & & 5 & $1-11$ & \\
\hline \multirow[t]{2}{*}{ Arthritis } & Yes & 18.89 & 1.605 & $1.49-1.73$ & 5 & $2-12$ & $<0.001$ & 24.47 & 1.382 & $1.32-1.45$ & 7 & $3-15$ & $<0.001$ \\
\hline & No & 8.77 & & & 3 & $0-7$ & & 14.18 & & & 4 & $1-10$ & \\
\hline \multirow[t]{2}{*}{ Tuberculosis } & Yes & 15.87 & 1.542 & $1.36-1.75$ & 4 & $1-11$ & $<0.001$ & 20.89 & 1.285 & $1.15-1.43$ & 6 & $2-14$ & $<0.001$ \\
\hline & No & 9.44 & & & 3 & $1-8$ & & 17.19 & & & 5 & $2-12$ & \\
\hline \multirow[t]{2}{*}{ Asthma } & Yes & 20.65 & 1.638 & $1.41-1.91$ & 5 & $1-13$ & $<0.001$ & 27.27 & 1.417 & $1.30-1.54$ & 8 & $3-17$ & $<0.001$ \\
\hline & No & 9.44 & & & 3 & $1-8$ & & 16.82 & & & 5 & $2-12$ & \\
\hline \multirow[t]{2}{*}{ Hepatitis B } & Yes & 13.36 & 1.434 & $1.25-1.64$ & 4 & $1-10$ & $<0.001$ & 18.99 & 1.297 & $1.10-1.53$ & 5 & $2-13$ & $<0.001$ \\
\hline & No & 9.5 & & & 3 & $1-8$ & & 17.3 & & & 5 & $2-12$ & \\
\hline \multirow[t]{2}{*}{ Atopic dermatitis } & Yes & 18.82 & 1.801 & $1.54-2.10$ & 5 & $1-12$ & $<0.001$ & 26.83 & 1.525 & $1.31-1.78$ & 8 & $2-16$ & $<0.001$ \\
\hline & No & 9.46 & & & 3 & $1-8$ & & 17.18 & & & 5 & $2-12$ & \\
\hline \multirow[t]{2}{*}{ Allergic rhinitis } & Yes & 12.62 & 1.348 & $1.25-1.46$ & 4 & $1-9$ & $<0.001$ & 22.72 & 1.378 & $1.24-1.53$ & 6 & $2-14$ & $<0.001$ \\
\hline & No & 9.33 & & & 3 & $0-8$ & & 17.11 & & & 5 & $2-12$ & \\
\hline \multirow[t]{2}{*}{ Cataract } & Yes & 16.2 & 1.28 & $1.11-1.47$ & 4 & $1-11$ & $<0.001$ & 23.33 & 1.103 & $1.05-1.16$ & 7 & $3-15$ & $<0.001$ \\
\hline & No & 9.46 & & & 3 & $1-8$ & & 15.74 & & & 5 & $1-11$ & \\
\hline
\end{tabular}

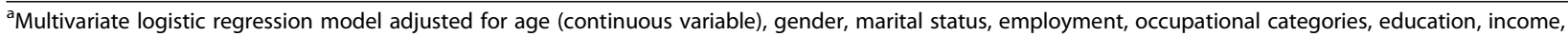
residence location and each disease

${ }^{\mathrm{b}} 95 \% \mathrm{CL} ; 95 \%$ confidence limits

${ }^{c}$ CES-D-K; Korean version of the Center for Epidemiological Studies Depression

${ }^{d}$ P-values were obtained using Student's t-test with the CES-D-K scores transformed by natural logarithm

underlying biological mechanisms, the physical and mental impairments and the symptoms of chronic diseases when assessing depressive symptoms in patients with MCDs. Biopsychosocial health care is necessary for adults with certain chronic diseases or MCDs [16].

It is important to note that the RRs of experiencing depressive symptoms were higher in the middle-aged population than in the elderly population for all chronic diseases except stroke and allergic rhinitis. This result indicates that the difference in depressive symptoms between middle-aged individuals with and without chronic diseases is greater than that between elderly individuals with and without chronic diseases. In particular, the RRs of a middle-aged patient with 3 or more diseases experiencing depressive symptoms increased dramatically.

In fact, according to several studies, older adults with chronic diseases are less likely to report worse healthrelated outcomes than younger adults, including physical impairments and mental health problems, such as sleep disturbances and life stress. Younger adults had more negative perceptions and emotions related to their diseases. Moreover, an awareness of chronic diseases could 
Table 3 Prevalence and Risk ratios of depressive symptoms according to the presence of multiple chronic diseases

\begin{tabular}{|c|c|c|c|c|c|c|c|c|c|c|c|c|c|}
\hline & & $40-59 \mathrm{yr}$ & & & & & & $\geq 60 \mathrm{yr}$ & & & & & \\
\hline & & (No. particip & ants $=88,7$ & & & & & (No. particip & ants $=67,9$ & & & & \\
\hline & & Prevalence & Adjusted & $95 \% \mathrm{CL}^{b}$ & CES-D-KC & & & Prevalence & Adjusted & $95 \% \mathrm{CL}^{b}$ & CES-D-Kc & & \\
\hline & & & risk ratio ${ }^{a}$ & & Median & IQR & $p^{d}$ & & risk ratio ${ }^{a}$ & & Median & $\mathrm{IQR}$ & $p^{d}$ \\
\hline No. of diseases & 0 & 7.67 & & & 3 & $0-7$ & $<0.001$ & 10.78 & & & 4 & $1-9$ & $<0.001$ \\
\hline & 1 & 10.7 & 1.429 & $1.35-1.51$ & 3 & $1-8$ & & 14.22 & 1.222 & $1.15-1.30$ & 4 & $1-10$ & \\
\hline & 2 & 14.95 & 1.879 & $1.74-2.03$ & 4 & $1-11$ & & 18.03 & 1.468 & $1.37-1.57$ & 6 & $2-12$ & \\
\hline & 3 & 20.88 & 2.602 & $2.32-2.92$ & 5 & $2-13$ & & 24.12 & 1.93 & $1.80-2.07$ & 7 & $3-15$ & \\
\hline & 4 or more & 33.72 & 4.465 & $3.81-5.23$ & 8 & $3-19$ & & 32.09 & 2.643 & $2.45-2.85$ & 10 & $4-19$ & \\
\hline Multiple chronic & No & 8.49 & & & 3 & $0-7$ & $<0.001$ & 12.65 & & & 4 & $1-9$ & $<0.001$ \\
\hline eases & Yes & 17.8 & 1.939 & $1.82-2.06$ & 5 & $1-12$ & & 22.75 & 1.620 & $1.55-1.69$ & 7 & $2-14$ & \\
\hline
\end{tabular}

${ }^{a}$ Multivariate logistic regression model adjusted for age (continuous variable), gender, marital status, employment, occupational categories, education, income and residence location

b5\% CL; 95\% confidence limits

${ }^{c}$ CES-D-K; Korean version of Center for epidemiological studies depression

${ }^{\mathrm{d}} \mathrm{P}$-values were obtained by Student's t-test or ANOVA using CES-D-K score transformed by natural logarithm

also affect emotional disorders [40]. In particular, middleaged adults have many roles in social and familial activities; therefore, disease awareness at an early age of onset, role limitations, and impairments may cause a number of psychological problems [41-43]. The depressive symptoms associated with chronic diseases have various causes, such as the increased risk of complications [4], increased economic loss due to healthcare utilization and cost [44], increased functional disabilities [45], limitations of physical activity [8], and loss of productive work time [46]. These psychosocial burdens are more prevalent in middleaged adults than in elderly adults.

In addition, the relationship between depressive symptoms and chronic diseases is strengthened in socially active groups. This observation indicates that depression is also strongly associated with limitations in social and physical activities, as well as the psychosocial burden. As an example, a Dutch study reported that there was no relationship between depressive symptoms and diseases after adjustment for physical limitations in stroke patients [8].

Comparing men and women, the prevalence of depressive symptoms in women is higher and the RRs were similar except, the RR in the middle-aged women with 4 or more diseases was significantly higher than those in the other groups. According to several previous studies, women in the general population have more severe depressive episodes with increased functional impairment and are more likely to develop depression than men [47]. Therefore, in middle-aged women whose social functioning is important, more chronic diseases are associated with the development of increased depressive symptoms. Further studies are needed to explore the biological factors, such as hormonal changes and menopause, associated with susceptibility to depressive symptoms in middle-aged women with MCDs.
Diseases (or symptoms) that share disease-associated cellular components (genes, proteins, metabolites, miRNAs) show comorbidity [48]. The relationship between depressive symptoms and chronic diseases is bidirectional. Many symptoms of chronic diseases cause depression, but depression is also a risk factor or aggravating factor that affects a patient's health behavior, the patient-physician relationship, self-care (e.g., diet, exercise, and smoking cessation) [2], and the biological inflammation mechanism. Therefore, new chronic diseases are likely to affect patients with depression due to poor self-management as well as the presence of biological inflammatory mediators, such as IL-6 and C-reactive protein (CRP) [38, 49]. Additionally, someone with one chronic disease has a higher chance of developing other chronic conditions because the functional and biological mechanisms are common $[26,49,50]$. Therefore, there is an increased possibility that MCDs may develop in a depressed patient [51]. Clouse et al. [35] reported that the recognition and treatment of depression in diabetic women reduced the occurrence of diabetic complications.

This study has several limitations. First, the study has a cross-sectional design. Therefore, the causal relationship between depressive symptoms and MCDs is unclear. Second, this study was a questionnaire survey conducted by a trained interviewer; therefore, only depressive symptoms were evaluated. However, the relationship between major depression and MCD could be better elucidated in future health surveys using structural diagnostic interviews conducted by psychologists or psychiatrists. Third, chronic diseases diagnosed by medical doctors were investigated; however, information bias could occur because the past medical history questionnaires were self-reported. Fourth, diseases known to be risk factors for depression, such as chronic renal failure and pulmonary diseases were excluded from the 
2009 KCHS [15, 42]. In particular, Pruchno et al. [15] reported that patients with MCDs that included pulmonary diseases had the highest odds of experiencing depression.

Despite these limitations, our study has several strengths. First, this study used the data from a large population-based sample that is representative of Korea. Second, this study used the face-to-face interview method, which has a high reliability and validity for the assessment of mental disorders [52]. In addition, this study has particular significance in aspects of public health as well as clinical issues. From the clinical perspective, the careful observation and assessment of depressive symptoms should be actively pursued in health care clinics in patients with chronic diseases, particularly when the number of chronic diseases increases, from vulnerable groups, such as the middle-aged population. From the public health perspective, attention should be paid to depressive symptoms, and an environment that improves the ability of individuals suffering from MCDs to participate in social and physical activities should be created at the community level.

\section{Conclusions}

In conclusion, the association between MCDs and depressive symptoms was constant across the transition from the middle-aged to the elderly years. Therefore, special attention should be paid to the middle-aged population with MCDs as well as the elderly population. In addition, a comprehensive clinical evaluation that considers age, gender, and the number of diseases should be performed in individuals with MCDs and depressive symptoms.

\section{Additional files}

Additional file 1: Table 1. Prevalence and Risk ratios of depressive symptoms according to diseases number, age and gender (DOCX 19 kb)

Additional file 2: Figure 2a. Rate ratios of experiencing depressive symptoms by the number of diseases in men aged 40-59 yr. Figure $\mathbf{2 b}$. Rate ratios of experiencing depressive symptoms by the number of diseases in women aged 40-59 yr. Figure $\mathbf{2 c}$. Rate ratios of experiencing depressive symptoms by the number of diseases in men aged $\geq 60 \mathrm{yr}$. Figure $\mathbf{2 d}$. Rate ratios of experiencing depressive symptoms by the number of diseases in women aged $\geq 60 \mathrm{yr}$. (PDF $108 \mathrm{~kb}$ )

\section{Abbreviations}

CES-D-K: Korean version of the Center for Epidemiologic Studies Depression Scale; CL: Confidence limit; CRP: C-reactive protein; IL: Interleukin; IQR: Interquartile range; KCDC: Korean Centers for Disease Control and Prevention; KCHS: Korean Community Health Survey; MCDs: Multiple chronic diseases; PSD: Post-stroke depression; RR: Risk ratio

\section{Acknowledgements}

The authors appreciate all citizens who participated in the 2009 KCHS and all members of the 2009 KCHS team.

\section{Funding}

This work was supported by a grant from the Korean Centers for Disease Control and Prevention, Ministry of Health and Welfare (2010-02-CON-22-P).

\section{Availability of data and materials}

The datasets generated and/or analyzed during the current study are publicly available in the Korean Community Health Survey repository, [https://chs.cdc.go.kr/chs/intro.html].

\section{Authors' contributions}

JY Seo conducted the literature review, performed the statistical analysis, and wrote and revised the manuscript. BY Choi suggested the study concept and directed the implementation of the study, including quality assurance and control. SA Kim and HY Lee participated in collecting and cleaning the data. SA Kim participated in refining the manuscript. DH Oh supervised the study, participated in the literature review, provided feedback on successive drafts, and critically reviewed the manuscript. All authors read and approved the final manuscript.

Ethics approval and consent to participate

The KCHS protocol is annually reviewed and approved by the institutional review board of the KCDC. Written informed consent was obtained from all participants in the KCHS. No additional institutional review board approval was required for this study because the data were intended for public purposes.

Consent for publication

Not applicable.

\section{Competing interests}

The authors declare that they have no competing interests.

\section{Publisher's Note}

Springer Nature remains neutral with regard to jurisdictional claims in published maps and institutional affiliations.

\section{Author details}

${ }^{1}$ Institute for Health and Society, College of Medicine, Hanyang University, 222 Wangsimni-ro, Sungdong-Gu, Seoul 04763, South Korea. Department of Preventive Medicine, College of Medicine, Hanyang University, Seoul, South Korea. ${ }^{3}$ Center for Farmers' Safety \& Health, Dankook University Hospital, Cheonan, South Korea. ${ }^{4}$ Seulha Mental Health Clinic, Jeju, South Korea.

Received: 13 April 2017 Accepted: 22 September 2017

Published online: 25 October 2017

\section{References}

1. Spangenberg L, Forkmann T, Brahler E, Glaesmer $H$. The association of depression and multimorbidity in the elderly: implications for the assessment of depression. Psychogeriatrics. 2011;11(4):227-34.

2. Katon WJ. Epidemiology and treatment of depression in patients with chronic medical illness. Dialogues Clin Neurosci. 2011;13(1):7-23.

3. Boing AF, Melo GR, Boing AC, Moretti-Pires RO, Peres KG, Peres MA. Association between depression and chronic diseases: results from a population-based study. Rev Saude Publica. 2012;46(4):617-23.

4. de Groot M, Anderson R, Freedland KE, Clouse RE, Lustman PJ. Association of depression and diabetes complications: a meta-analysis. Psychosom Med. 2001;63(4):619-30.

5. Anderson RJ, Freedland KE, Clouse RE, Lustman PJ. The prevalence of comorbid depression in adults with diabetes: a meta-analysis. Diabetes Care. 2001;24(6):1069-78.

6. Findley $P$, Shen $C$, Sambamoorthi U. Multimorbidity and persistent depression among veterans with diabetes, heart disease, and hypertension. Health Social Work. 2011;36(2):109-19.

7. Chang CK, Hayes RD, Broadbent M, Fernandes AC, Lee W, Hotopf M, Stewart R. All-cause mortality among people with serious mental illness (SMI), substance use disorders, and depressive disorders in southeast London: a cohort study. BMC Psychiatry. 2010;10:77.

8. Bisschop MI, Kriegsman DM, Deeg DJ, Beekman AT, van Tilburg W. The longitudinal relation between chronic diseases and depression in older persons in the community: the Longitudinal Aging Study Amsterdam. J Clin Epidemiol. 2004;57(2):187-94. 
9. Harpole LH, Williams JW Jr, Olsen MK, Stechuchak KM, Oddone E, Callahan CM, Katon WJ, Lin EH, Grypma LM, Unutzer J. Improving depression outcomes in older adults with comorbid medical illness. Gen Hosp Psychiatry. 2005;27(1):4-12.

10. Palinkas LA, Wingard DL, Barrett-Connor E. Chronic illness and depressive symptoms in the elderly: a population-based study. J Clin Epidemiol. 1990; 43(11):1131-41.

11. Fiest KM, Currie SR, Williams JV, Wang J. Chronic conditions and major depression in community-dwelling older adults. J Affect Disord. 2011;131(1-3):172-8.

12. Jorm AF, Reavley NJ. Depression and stigma: from attitudes to discrimination. Lancet. 2013;381(9860):10-1.

13. Barnett K, Mercer SW, Norbury M, Watt G, Wyke S, Guthrie B. Epidemiology of multimorbidity and implications for health care, research, and medical education: a cross-sectional study. Lancet. 2012;380(9836):37-43.

14. Marengoni A, Angleman S, Melis R, Mangialasche F, Karp A, Garmen A, Meinow B, Fratiglioni L. Aging with multimorbidity: a systematic review of the literature. Ageing Res Rev. 2011;10(4):430-9.

15. Pruchno RA, Wilson-Genderson M, Heid AR. Multiple chronic condition combinations and depression in community-dwelling older adults. J Gerontol A Biol Sci Med Sci. 2016;0:1-3.

16. Wild B, Heider D, Maatouk I, Slaets J, Konig HH, Niehoff D, Saum KU, Brenner H, Sollner W, Herzog W. Significance and costs of complex biopsychosocial health care needs in elderly people: results of a population-based study. Psychosom Med. 2014;76(7):497-502.

17. Rodic D, Meyer AH, Meinlschmidt G. The Association between Depressive Symptoms and Physical Diseases in Switzerland: A Cross-Sectional General Population Study. Front Public Health. 2015;3:47

18. O'Connor K, Vizcaino M, Ibarra JM, Balcazar H, Perez E, Flores L, Anders RL. Multimorbidity in a Mexican community: secondary analysis of chronic illness and depression outcomes. Int J Nurs. 2015;2(1):35-47.

19. Bhattacharya R, Shen C, Sambamoorthi U. Excess risk of chronic physical conditions associated with depression and anxiety. BMC Psychiatry. 2014;14:10.

20. Pruchno RA, Wilson-Genderson M, Heid AR. Multiple Chronic Condition Combinations and Depression in Community-Dwelling Older Adults. J Gerontol A Biol Sci Med Sci. 2016;0:4-6.

21. Egede LE. Effect of comorbid chronic diseases on prevalence and odds of depression in adults with diabetes. Psychosom Med. 2005;67(1):46-51.

22. Vision and Strategy [https://chs.cdc.go.kr/chs/sub01/sub01_02.jsp].

23. Oh DH, Park JH, Lee HY, Kim SA, Choi BY, Nam JH. Association between living arrangements and depressive symptoms among older women and men in South Korea. Soc Psychiatry Psychiatr Epidemiol. 2015;50(1):133-41.

24. Kim YT, Choi BY, Lee KO, Kim H, Chun JH, Kim SY, Lee DH, Ghim YA, Lim DS, Kang YW, et al. Overview of Korean Community Health Survey. J Korean Med Assoc. 2012;55(1):74-83.

25. Carlsson AC, Wandell P, Osby U, Zarrinkoub R, Wettermark B, Ljunggren G. High prevalence of diagnosis of diabetes, depression, anxiety, hypertension, asthma and COPD in the total population of Stockholm, Sweden-a challenge for public health. BMC Public Health. 2013;13:670

26. van Oostrom SH, Picavet HS, van Gelder BM, Lemmens LC, Hoeymans N, van Dijk CE, Verheij RA, Schellevis FG, Baan CA. Multimorbidity and comorbidity in the Dutch population-data from general practices. BMC Public Health. 2012;12:715.

27. Kang HY, Yoo H, Park W, Go U, Jeong E, Jung KS, Son H. Tuberculosis Notification Completeness and Timeliness in the Republic of Korea During 2012-2014. Osong Public Health Res Perspect. 2016;7(5):320-6.

28. Chiu LY, Stewart K, Woo C, Yatham LN, Lam RW. The relationship between burnout and depressive symptoms in patients with depressive disorders. J Affect Disord. 2015;172:361-6.

29. Hill RM, Yaroslavsky I, Pettit JW. Enhancing depression screening to identify college students at risk for persistent depressive symptoms. J Affect Disord. 2015;174:1-6.

30. Ross CE, Mirowsky J. Components of depressed mood in married men and women. The Center for Epidemiologic Studies' Depression Scale. Am J Epidemiol. 1984;119(6):997-1004.

31. Park JH, Kim KW. A review of the epidemiology of depression in Korea. J Korean Med Assoc. 2011;54(4):362-9.

32. Cho MJ, Kim KH. Diagnostic validity of the CES-D(Korean version) in the assessment of DSM-III-R major depression. J Korean Neuropsychiatr Assoc. 1993;32(3):381-99.

33. Cho MJ, Nam JJ, Suh GH. Prevalence of symptoms of depression in a nationwide sample of Korean adults. Psychiatry Res. 1998;81(3):341-52.
34. Oh DH, Kim SA, Lee HY, Seo JY, Choi BY, Nam JH. Prevalence and correlates of depressive symptoms in korean adults: results of a 2009 korean community health survey. J Korean Med Sci. 2013;28(1):128-35.

35. Clouse RE, Lustman PJ, Freedland KE, Griffith LS, McGill JB, Carney RM. Depression and coronary heart disease in women with diabetes. Psychosom Med. 2003;65(3):376-83.

36. Kroemeke A. Depressive symptom trajectories over a 6-year period following myocardial infarction: predictive function of cognitive appraisal and coping. J Behav Med. 2016;39(2):181-91.

37. Mandliya A, Das A, Unnikrishnan JP, Amal MG, Sarma PS, Sylaja PN. Poststroke Fatigue is an Independent Predictor of Post-stroke Disability and Burden of Care: A Path analysis Study. Top Stroke Rehabil. 2016;23(1):69-76.

38. Robinson RG, Spalletta G. Poststroke depression: a review. Can J Psychiatr. 2010;55(6):341-9.

39. Alghwiri AA. The Correlation between Depression, Balance, and Physical Functioning Post Stroke. J Stroke Cerebrovasc Dis. 2016;25(2):475-9.

40. Meurs M, Roest AM, Wolffenbuttel BH, Stolk RP, de Jonge P, Rosmalen JG. Association of Depressive and Anxiety Disorders With Diagnosed Versus Undiagnosed Diabetes: An Epidemiological Study of 90,686 Participants. Psychosom Med. 2016;78(2):233-41.

41. O'Donnell S, Rusu C, Hawker GA, Bernatsky S, McRae L, Canizares M, MacKay C, Badley EM. Arthritis has an impact on the daily lives of Canadians young and old: results from a population-based survey. BMC Musculoskelet Disord. 2015;16:230

42. Laudanski K, Nowak Z, Niemczyk S. Age-related differences in the quality of life in end-stage renal disease in patients enrolled in hemodialysis or continuous peritoneal dialysis. Med Sci Monit. 2013;19:378-85.

43. Berry CE, Han MK, Thompson B, Limper AH, Martinez FJ, Schwarz MI, Sciurba FC, Criner GJ, Wise RA. Older adults with chronic lung disease report less limitation compared with younger adults with similar lung function impairment. Ann Am Thorac Soc. 2015;12(1):21-6.

44. Egede LE, Zheng D, Simpson K. Comorbid depression is associated with increased health care use and expenditures in individuals with diabetes. Diabetes Care. 2002;25(3):464-70.

45. Egede LE. Diabetes, major depression, and functional disability among U.S. adults. Diabetes Care. 2004;27(2):421-8.

46. Egede LE. Effects of depression on work loss and disability bed days in individuals with diabetes. Diabetes Care. 2004;27(7):1751-3.

47. Gottlieb SS, Khatta M, Friedmann E, Einbinder L, Katzen S, Baker B, Marshall J, Minshall S, Robinson S, Fisher ML, et al. The influence of age, gender, and race on the prevalence of depression in heart failure patients. J Am Coll Cardiol. 2004:43(9):1542-9.

48. Barabasi AL, Gulbahce N, Loscalzo J. Network medicine: a network-based approach to human disease. Nat Rev Genet. 2011;12(1):56-68.

49. Friedman EM, Christ SL, Mroczek DK. Inflammation Partially Mediates the Association of Multimorbidity and Functional Limitations in a National Sample of Middle-Aged and Older Adults: The MIDUS Study. J Aging Health. 2015:27(5):843-63.

50. Agborsangaya CB, Lau D, Lahtinen M, Cooke T, Johnson JA. Multimorbidity prevalence and patterns across socioeconomic determinants: a crosssectional survey. BMC Public Health. 2012;12:201.

51. Cho MJ, Lee JY, Kim BS, Lee HW, Sohn JH. Prevalence of the major mental disorders among the Korean elderly. J Korean Med Sci. 2011;26(1):1-10.

52. Hajebi A, Motevalian A, Amin-Esmaeili M, Hefazi M, Radgoodarzi R, RahimiMovaghar A, Sharifi V. Telephone versus face-to-face administration of the Structured Clinical Interview for Diagnostic and Statistical Manual of Mental Disorders, Fourth Edition, for diagnosis of psychotic disorders. Compr Psychiatry. 2012;53(5):579-83. 